\title{
Isolation and Identification of Symbiotic Bacteria from Brasenia schreberi and Analysis of their Polysaccharide Producing Characteristics and Antioxidant Activity
}

\author{
Chenglong Li1", Xueyang Song1\#, Qiuyu Zhang², Hanyu Gong2, Guanghui Yu1,2* \\ ${ }^{1}$ China Brasenia schreberi Research Institute, College of Life Sciences, South-Central University for Nationalities, \\ Wuhan, China \\ ${ }^{2}$ Hubei Provincial Key Laboratory for Protection and Application of Special Plants in Wuling Area of China, South-Central \\ University for Nationalities, Wuhan, China \\ Email: *yusheen@163.com, 491732884@qq.com, 595825175@qq.com,645649146@qq.com, hygong@mail.scuec.edu.cn
}

How to cite this paper: Li, C.L., Song, X.Y., Zhang, Q.Y., Gong, H.Y. and Yu, G.H. (2020) Isolation and Identification of Symbiotic Bacteria from Brasenia schreberi and Analysis of their Polysaccharide Producing Characteristics and Antioxidant Activity. American Journal of Plant Sciences, 11, 307-322.

https://doi.org/10.4236/ajps.2020.113023

Received: January 13, 2020

Accepted: March 3, 2020

Published: March 6, 2020

Copyright () 2020 by author(s) and Scientific Research Publishing Inc. This work is licensed under the Creative Commons Attribution International License (CC BY 4.0).

http://creativecommons.org/licenses/by/4.0/

(c) (i) Open Access

\begin{abstract}
Brasenia schreberi (water shield), a perennial freshwater aquatic plant of the family Nymphaeaceae, is rich in polysaccharides with positive biological activity and potential application value. As an indicator plant of the environment in wetlands, $B$. schreberi original and wild water environment faced increasing deterioration and has been listed as a critically endangered species in several countries of East Asia. Seeking an alternative method to produce $B$. schreberi mucilage polysaccharide is of top priority. The morphological structure of the stem and leaf of $B$. schreberi was studied. Well-developed glandular cells and aerenchyma tissue were observed in the stem and leaves of water shield, which were related to its aquatic habitat and polysaccharide secretion and then three endophytic bacteria were successfully isolated and purified from its stem and leaf and identified as Micromonospora sp. YG-1, Xylariaceae sp. strain UT-X and Psychrobacter pulmonis strain T-15. Symbiotic bacteria from $B$. schreberi produced polysaccharides with similar spectral peaks and chemical functional groups to those of $B$. chinensis. Further, analysis of hydroxyl free radicals showed that symbiotic bacteria in water shield had significant antioxidant activity against hydroxyl free radicals. This study provides a theoretical and practical basis for further study using symbiotic bacteria to produce polysaccharides to overcome the environmental limitations of the growth and development of B. schreberi.
\end{abstract}




\section{Keywords}

Brasenia schreberi, Endosymbiont, HPLC, IR Spectrum, Polysaccharide

\section{Introduction}

Extracellular polysaccharides are attracting increasing attention in the field of medicine because of their positive biological activity and potential application value [1]. Research revealed that extracellular polysaccharides produced by two marine microorganisms, Fusarium oxysporum and Aspergillus ochraceus, showed strong anti-lipid peroxidation ability and free-radical (e.g. superoxide anions) scavenging potential [2] and extracellular oligosaccharides of an endophytic bacteria (14-DS-1) found in Codonopsis pilosula activate macrophages of the immune system and affect their migration ability and microfilament morphology [3]. Moreover, evidence indicates that they can affect normal spindle formation and induce cells to tend to stagnate in the $\mathrm{S}$ phase and increase the apoptotic rate. One possible mechanism to achieve this effect would involve the capacity of extracellular polysaccharides to affect spindle-related precise regulation and DNA synthesis during the cell cycle [3]. Similarly, antineoplastic polysaccharides extracted from mushrooms were shown to enhance the immune response in vivo and in vitro and act as a modifier of biological reactions [1].

Recent studies have revealed the promising clinical role of extracellular polysaccharides from multiple plants [4] [5], including Brasenia schreberi [6] [7]. B. schreberi, also known as water shield, horseshoe, lake vegetable, water anemone, sunflower and lotus leaf or cauliflower, is a perennial floating-leaf aquatic plant belonging to the family Nymphaeaceae [8] [9]. The main component of the viscous mucilage on the surface of $B$. schreberi is a viscous polysaccharide [10] with exceptionally high nutritional value and protection role [11]. As an indicator plant of the environment in wetlands, B. schreberi growth demands a high-quality water [12]. However, in recent years, habitat fragmentation and loss and human disturbance have led to a higher organic content in the original and wild water environment, causing a deterioration in the wild-living condition of B. schreberi [12]. Moreover, B. schreberi has been recently listed as a critically endangered species in several countries of East Asia [13]. In this context, seeking an alternative method to produce $B$. schreberi mucilage polysaccharide is of top priority.

Given that plants and their symbiotic endophytes can produce the same or similar functionally active ingredients, endophytes may be an important source of new active natural products [14]. Endophytes are microorganisms that survive in healthy plant tissues during part or all of their life cycles without causing obvious infection symptoms in their host. For example, previous results showed that Erwinia sp. SS2, an endosymbiotic bacterium found in Chinese yam, showed the ability to produce extracellular polysaccharides [15]. Further, a pre- 
vious study showed that there are many gum-producing bacteria in the viscose polysaccharide of $B$. schreberi [16]. To comprehensively utilize B. schreberi and seek alternative bacteria that can produce mucilage polysaccharide similar to $B$. schreberi, this study aimed to isolate potential symbiotic bacteria from $B$. schreberi and study their polysaccharide-producing characteristics.

\section{Materials and Methods}

\subsection{Experimental Materials}

Stems and leaves of $B$. schreberi were obtained from Fubaoshan Nature Reserve in Lichuan, Hubei Province. These were rinsed with 30\% hydrogen peroxide and then with distilled water for further use.

\subsection{Isolation of Endophytic Bacteria from B. schreberi}

Stems, leaves and roots of $B$. Schreberi were sterilized with $0.1 \%$ mercury for 10 min and rinsed with distilled water several times in a sterile environment. Thereafter, these were inoculated on LB solid medium and cultured in the dark. Three kinds of well-growing colonies were selected from the medium and transferred to the new LB medium plate. The colonies were purified and numbered as No. 1, No. 2 and No. 3. In addition, the flourishing bacteria were preserved in glycerol suspension for subsequent experiments.

\subsection{Identification of Endophytic Bacteria in B. schreberi}

The 16S rDNA sequence of bacteria (27F/1492R primer) or ITS sequence of fungi (ITS1 and ITS4 primer) were amplified based on standard procedure of bacteria/fungi identification, which is exerted by. The amplified products were sequenced by the Sanger method. The sequencing results were compared and analyzed on NCBI website (https://blast.ncbi.nlm.nih.gov/Blast.cgi). Cases of homology greater than $97 \%$ and highest homology were used to identify the candidate species of endophytic bacteria.

$16 \mathrm{~S}$ rDNA sequence amplification primer sequence:

Primer 1 27F: 5-AGAGTTTGATCCTGGCTCAG-3'

Primer 2 1492R: 5'TACGGCTACCTTGTTACGACTT-3'

The size of amplified fragments is approximately $1400-1700 \mathrm{bp}$

ITS sequence amplification primer sequence:

Primer 1 ITS1: 5 'TCCGTAGGTGAACCTGCGG-3'

Primer 2 ITS4: 5 '-TCCTCCGCTTATTGATATGC-3'

The size of amplified fragments is approximately $400-700 \mathrm{bp}$

\subsection{Purification and Extraction of Polysaccharides from the Endosymbiont}

Strains were selected from the plate of LB medium and transferred to the purified strains. The strains were inoculated into the liquid LB medium. The fermentation liquid was centrifuged for $5 \mathrm{~min}$ at $200 \mathrm{rpm}$ and incubated at $37^{\circ} \mathrm{C}$ overnight for 2 days. The supernatant was obtained after centrifugation at 12,000 
rpm for $5 \mathrm{~min}$. Next, the supernatant and the organic solution were mixed with chloroform-n-butanol solution (chloroform: $n$-butanol $=4: 1$ ) at a 3:1 ratio for extraction in a centrifugal tube. The supernatant was oscillated for $20-30 \mathrm{~min}$ and centrifuged at $8000 \mathrm{rpm}$ for $10 \mathrm{~min}$. Precipitated protein between the two phases could not be discarded; thus, it continued to be removed five times according to the above operation. Then, the supernatant was filtered twice with a $0.45-\mu \mathrm{m}$ micron membrane. After filtration, it was heated and concentrated to $1 / 2-2 / 3$ of its original volume at $70^{\circ} \mathrm{C}$. Thereafter, it was added with a 4 -fold volume of $95 \%$ ethanol. Finally, the supernatant was frozen overnight in a refrigerator and centrifuged at $12,000 \mathrm{rpm}$ for $10 \mathrm{~min}$. The precipitate was considered the endophytic bacterial polysaccharide.

\subsection{Extraction and Separation of Crude Polysaccharide from $B$. schreberi}

Tender sprouts of $B$. schreberi were extracted in $\mathrm{NaOH}(0.1 \mathrm{~mol} / \mathrm{L})$; the ratio of material to liquid was $1: 2(\mathrm{w} / \mathrm{v})$ and the $\mathrm{pH}$ was adjusted to 7.0 after $1.5 \mathrm{~h}$ of alkali extraction at $25^{\circ} \mathrm{C}$. The sprouts were removed, the residues were separated by centrifugation and the supernatant was concentrated at $60^{\circ} \mathrm{C}$ for $1 \mathrm{~h}$ using a magnetic stirrer. Thereafter, the Sevage method was used to treat the concentrated crude extract repeatedly to remove the free protein and concentrate again to approximately $2 / 3$ of the original volume. A 4 -fold volume of absolute ethanol was added to precipitate overnight; thereafter, the mixture was centrifuged for $10 \mathrm{~min}$ at $4000 \mathrm{rpm}$ to obtain the precipitate. Next, a small amount of water was used to dissolve the precipitate, which was then concentrated and added with a 4 -fold volume of ethanol to precipitate overnight. This operation was repeated three times before final drying to obtain the B. schreberi polysaccharide (BSP).

\subsection{Determination of Sugar Content in the B. schreberi Polysaccharide Extract}

Polysaccharide content of BSP was determined by the phenol-sulfuric acid method and D-glucose as standard. First, D-glucose was used to prepare the standard curve solution $(0.1 \mathrm{mg} / \mathrm{ml})$. Second, the reference solutions were placed into the test tubes $(0.2,0.4,0.6,0.8$ and $1.0 \mathrm{ml})$ and the phenol solution was added to stabilize them. Then, concentrated sulfuric acid was quickly added for shaking. The tubes were allowed to stand for $10 \mathrm{~min}$ until cooled to room temperature and then the absorbance was measured at $490 \mathrm{~nm}$. Double distilled water (DDW) was used as the blank control. The results were analyzed by linear regression analysis. Thereafter, the absorbance level of the sample was measured to determine the content of glucuronic acid.

\subsection{Structural Analysis of Polysaccharides from B. schreberi and Comparison with Polysaccharides from Endophytes}

The chemical composition of polysaccharide samples was determined by high performance liquid chromatography (HPLC) using an Agilent 1260 Infinity II LC System equipped with a Shodex OH-pak SB-804 HQ column $(8 \mathrm{~mm} \times 300$ 
$\mathrm{mm})$. To further compare the glycosidic bonds of the polysaccharides between symbiotic bacteria and B. schreberi, the structure of polysaccharides was further analyzed by Fourier transform infrared spectroscopy (IR) (IRTracer-100).

\subsection{Determination of Antioxidant Activity of Polysaccharides}

In this experiment, the hydroxyl radical kit provided by Nanjing Jiancheng Bioengineering Institute was used to determine polysaccharide activity. The polysaccharide sample and reagent were mixed evenly and reacted at $37^{\circ} \mathrm{C}$ for $1 \mathrm{~min}$, after which the color reagent was added immediately to stop the reaction. After mixing evenly, the polysaccharide sample was placed at room temperature for 20 min. The spectrophotometer was zeroed with distilled water and the absorbance of each tube was measured at $550 \mathrm{~nm}$. The experimental results showed the scavenging of hydroxyl radicals and some antioxidant activities of the polysaccharides obtained.

\section{Results}

\subsection{There are Well-Developed Airways and Glandular Cells in the Stems and Leaves of $B$, schreberi}

The stomata were distributed on the upper epidermis of the leaves (Figure $1(\mathrm{~A})$ ). The lower epidermis of the leaves was in contact with water, so there were more stomata on the upper epidermis for photosynthesis and gas exchange. Mucilage was abundant on the dorsal surface of the stem and the leaf and there were many black stripes on the lower epidermis of the leaf. Study showed these structures were glandular cells. In addition, red dots and black stripes were observed, which might be symbiotic bacteria (Figure $1(B)$ ). There was a layer of pectin on the surface of the stem of fresh water shield. Under this pectin layer, there were glandular cells with a hollow airway in the middle to allow gas exchange (Figure $1(C)$ ). After incubation in the laboratory for a period of time, the glandular cells disappeared and there was no pectin on the surface of the stem (Figure 1(D)). Therefore, pectin secretion may be related to glandular cells.

\subsection{Isolation of Endophytes}

The three colonies grew well in the LB medium plate. Among them, the diameter of colony No. 1 was approximately $1-2 \mathrm{~mm}$, its shape was regular, round, smooth and tidy edged and was wet and milky yellow, with a transparent surface (Figure 2(A)); the diameter of colony No. 2 was approximately $4-6 \mathrm{~mm}$, the colony bulged, the edge was not smooth, the hypha was visible and the color was opaque white (Figure 2(B)); the diameter of colony No. 3 was $5 \mathrm{~mm}$ and the colony was round and milky white (Figure $2(\mathrm{C})$ ).

\subsection{Symbiosis of Bacteria and Fungi with B. schreberi}

According to the standard sequencing method of bacteria and fungi, the sequence of symbiotic bacteria B. schreberi was as follows: 

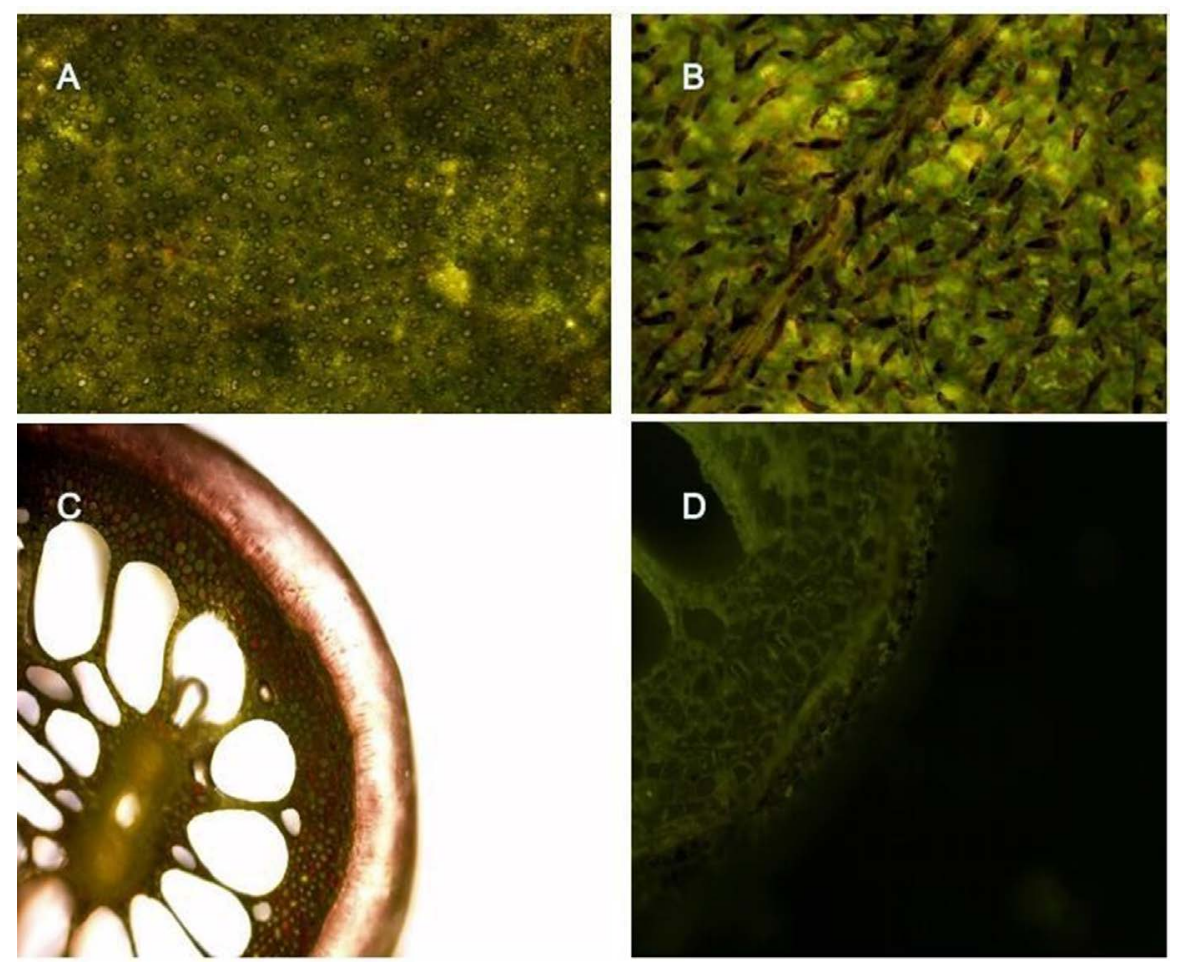

Figure 1. Transverse section of the stem and the leaf of Brasenia schreberi. (A) An upper epidermis of the leaf; (B) Lower epidermis of the leaf; (C) Transverse section of a fresh stem; (D) Transverse section of a stem grown in culture.

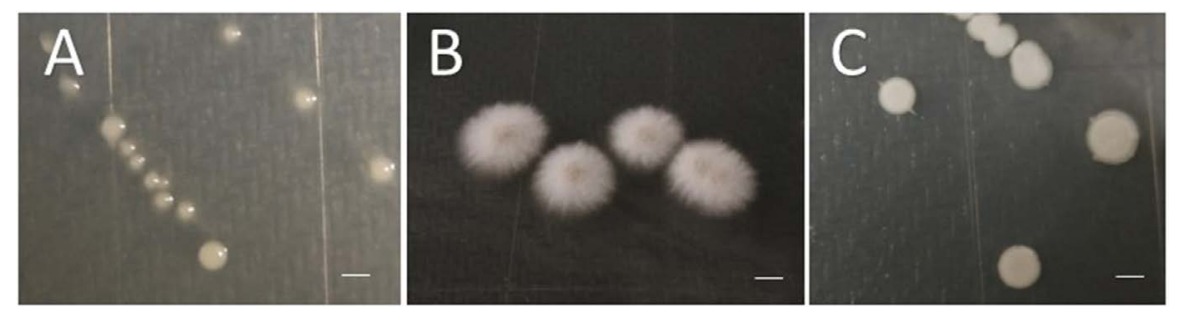

Figure 2. Morphology of the colonies of the three endophytic bacteria from Brasenia schreberi. (A) colony No. 1; (B) colony No. 2; (C) colony No. 3 (Bars = $2 \mathrm{~mm}$ ).

No. 1:

GCATGGCAGCGCTAGAGTTGCTCCTGGAGCGGAAGGCCCTTCGGGG TACTCGAGCGGCGAACGGGTGAGTAACACGTGAGTAACCTGCCCCAGG CTTTGGGATAACCCTCGGAAACGGGGGCTAATACCGAATATGACCTCC GGACGCATGTTTGGTGGTGGAAAGTTTTTCGGCCTGGGATGGGCTCGC GGCCTATCAGCTTGTTGGTGGGGTGATGGCCTACCAAGGCGACGACGG GTAGCCGGCCTGAGAGGGCGACCGGCCACACTGGGACTGAGACACGG CCCAGACTCCTACGGGAGGCAGCAGTGGGGAATATTGCACAATGGGC GGAAGCCTGATGCAGCGACGCCGCGTGAGGGATGACGGCCTTCGGGT TGTAAACCTCTTTCAGCAGGGACGAAGCGTAAGTGACGGTACCTGCAG AAGAAGCGCCGGCCAACTACGTGCCAGCAGCCGCGGTAAGACGTAGG GCGCGAGCGTTGTCCGGATTTATTGGGCGTAAAGAGCTCGTAGGCGGC TTGTCGCGTCGACCGTGAAAACTTGGGGCTCAACCCCAAGCCTGCGGT 
CGATACGGGCAGGCTAGAGTTCGGTAGGGGAGACTGGAATTCCTGGTG TAGCGGTGAAATGCGCAGATATCAGGAGGAACACCGGTGGCGAAGGC GGGTCTCTGGGCCGATACTGACGCTGAGGAGCGAAAGCGTGGGGAGC GAACAGGATTAGATACCCTGGTAGTCCACGCTGTAAACGTTGGGCGCT AGGTGTGGGGGGCCTCTCCGGTTCCCTGTGCCGCAGCTAACGCATTAA GCGCCCCGCCTGGGGAGTACGGCCGCAAGGCTAAAACTCAAAGGAAT TGACGGGGGCCCGCACAAGCGGCGGAGCATGCGGATTAATTCGATGC AACGCGAAGAACCTTACCTGGGTTTGACATGGCCGCAAAACCTCCAGA GATGGGGGGTCCTTCGGGGGCGGTCACAGGTGGTGCATGGCTGTCGTC AGCTCGTGTCGTGAGATGTTGGGTTAAGTCCCGCAACGAGCGCAACCC TCGTTCGATGTTGCCAGCGCGTTATGGCGGGGACTCATCGAAGACTGC CGGGGTCAACTCGGAGGAAGGTGGGGATGACGTCAAGTCATCATGCC CCTTATGTCCAGGGCTTCACGCATGCTACAATGGCCGGTACAATGGGC TGCGATACCGTGAGGTGGAGCGAATCCCAAAAAGCCGGTCTCAGTTCG GATCGGGGTCTGCAACTCGACCCCGTGAAGTCGGAGTCGCTAGTAATC GCAGATCAGCAACGCTGCGGTGAATACGTTCCCGGGCCTTGTACACAC CGCCCGTCACGTCACGAAAGTCGTCAACGTAGGAAGTGCGGTGGCCCC ACCCTGGTGGAGGCAACGTTAGAGTAGAGCTATCCGCCC

No. 2:

GTAGGTTGAACCTGCGGAGGGATCATTACTGAGTTCTACAAAAAACT CCCAACCCTTTGTGAACCTTACCGTCGTTGCCTCGGCGCCGAGCGGCG GCTACCCTGGAGAAGCTACCCGGGAGCCACCTACCCTGTAGGTGGCTA CCCTGGAGCTACCCTGTAGTAGTTTGCATTCTACGCTCCGCCGGCGGA CCTTCTACACTCTGTTTTGTATAGTGTATCTCTGAAACCTATAACGTAA TACGTTAAAACTTTCAACAACGGATCTCTTGGTTCTGGCATCGATGAA GAACGCAGCGAAATGCGATACGTAATGTGAATTGCAGAATTCAGTGAA TCATCGAATCTTTGAACGCATATTGCGCCCATTAGTATTCTAGTGGGCA TGCCTATTCGAGCGTCATTTCAACCCTTACGCCCCTGTTGCGTAGTGTT GGGAACCTACAGGCCTGTAAAAAGGACCTGTAGCTCCCTAAAGGTAGT GGCGGTGTTAGGTACACTCGTAGCGTAGTAACATCTTTTCTCGCTCCTG CAGTGTACCTAAGGCCTGCCGTGAAAAACCCCCTATAACTTCTAGTGG TTGACTTCGGATTAGGTAGG

No. 3:

GAATGGCGGGCCGCTATAATGCTAGTCGAGCGAACAGATAAGGAGC TTGCTCCTTTGACGTTAGCGGCGGACGGGTGAGTAACACGTGGATAAC CTACCTATAAGACTGGGATAACTTCGGGAAACCGGAGCTAATACCGGA TAACATATTGAACCGCATGGTTCAATAGTGAAAGGCGGCTTTGCTGTC ACTTATAGATGGATCCGCGCCGTATTAGCTAGTTGGTAAGGTAACGGC TTACCAAGGCAACGATACGTAGCCGACCTGAGAGGGTGATCGGCCACA CTGGAACTGAGACACGGTCCAGACTCCTACGGGAGGCAGCAGTAGGG AATCTTCCGCAATGGGCGAAAGCCTGACGGAGCAACGCCGCGTGAGTG ATGAAGGTCTTCGGATCGTAAAACTCTGTTATCAGGGAAGAACAAATG TGTAAGTAACTGTGCACATCTTGACGGTACCTGATCAGAAAGCCACGG CTAACTACGTGCCAGCAGCCGCGGTAATACGTAGGTGGCAAGCGTTAT 
CCGGAATTATTGGGCGTAAAGCGCGCGTAGGCGGTTTTTTAAGTCTGA TGTGAAAGCCCACGGCTCAACCGTGGAGGGTCATTGGAAACTGGAAAA CTTGAGTGCAGAAGAGGAAAGTGGAATTCCATGTGTAGCGGTGAAATG CGCAGAGATATGGAGGAACACCAGTGGCGAAGGCGACTTTCTGGTCTG TAACTGACGCTGATGTGCGAAAGCGTGGGGATCAAACAGGATTAGATA CCCTGGTAGTCCACGCCGTAAACGATGAGTGCTAAGTGTTAGGGGGTT TCCGCCCCTTAGTGCTGCAGCTAACGCATTAAGCACTCCGCCTGGGGA GTACGACCGCAAGGTTGAAACTCAAAGGAATTGACGGGGACCCGCAC AAGCGGTGGAGCATGTGGTTTAATTCGAAGCAACGCGAAGAACCTTAC CAAATCTTGACATCCTTTGACCGCTCTAGAGATAGAGTCTTCCCCTTCG GGGGACAAAGTGACAGGTGGTGCATGGTTGTCGTCAGCTCGTGTCGTG AGATGTTGGGTTAAGTCCCGCAACGAGCGCAACCCTTAAGCTTAGTTG CCATCATTAAGTTGGGCACTCTAAGTTGACTGCCGGTGACAAACCGGA GGAAGGTGGGGATGACGTCAAATCATCATGCCCCTTATGATTTGGGCT ACACACGTGCTACAATGGACAATACAAAGGGCAGCTAAACCGCGAGG TCAAGCAAATCCCATAAAGTTGTTCTCAGTTCGGATTGTAGTCTGCAAC TCGACTACATGAAGCTGGAATCGCTAGTAATCGTAGATCAGCATGCTA CGGTGAATACGTTCCCGGGTCTTGTACACACCGCCCGTCACACCACGA GAGTTTGTAACACCCGAAGCCGGTGGAGTAACCATTTATGGAGCTAGC CGTCGAGTGGAGAGCTCAGTCT

The results of sequencing were compared and analyzed via browsing the NCBI website. The species with over $97 \%$ homology and highest homology were finally identified as endosymbiotic species. The results showed that two of the symbiotic bacteria isolated were bacteria (colonies No. 1 and No. 3), while the other was a fungus (colony No. 2) (Table 1). Endophytes were identified as $\mathrm{Mi}$ cromonospora sp.YG-1, Xylariaceae sp. strain UT-X and Psychrobacter pulmonis strain T-15.

\subsection{Extracts from the Fermentation Broth of Symbiotic Bacteria} Found in B. schreberi Contained Secreted Polysaccharides

Polysaccharide content in the fermentation broth of endophytic bacteria from $B$. schreberi was determined and compared. After polysaccharide was hydrolyzed by sulfuric acid, the content of secreted sugar in the bacterial solution was determined by DNS (3-amino-5-nitro salicylic acid) method. With D-glucuronic acid as the reference standard, the standard curve was drawn by the absorbance of different concentrations of standard glucose solution reacted with DNS reagent and sulfuric acid. The standard curve was $\mathrm{y}=0.0368 \mathrm{x}-0.0436\left(R^{2}=\right.$ 0.9807). The content of polysaccharides was determined according to this standard curve (Table 2). The results showed that the polysaccharide contents in the fermented extracts were as follows: $0.30 \pm 0.01 \mathrm{mg} / \mathrm{ml}$ in $B$. schreberi samples, $0.07 \pm 0.001 \mathrm{mg} / \mathrm{ml}$ in Micromonospora sp.YG-1, $0.07 \pm 0.002 \mathrm{mg} / \mathrm{ml}$ in Xylariaceae $s p$. strain UT-X and $0.06 \pm 0.001 \mathrm{mg} / \mathrm{ml}$ in Psychrobacter pulmonis strain T-15 (Table 2). 
Table 1. Species identification of three endophytic bacteria.

\begin{tabular}{ccc}
\hline Code & Homology & Species \\
\hline No. 1 & $99 \%(1354 / 137)$ & Micromonospora sp.YG-1 \\
No. 2 & $98 \%(563 / 575)$ & Xylariaceae sp. strain UT-X \\
No. 3 & $99 \%(1440 / 144)$ & Psychrobacter pulmonis strain T-15 \\
\hline
\end{tabular}

Table 2. Determination of polysaccharides from different species.

\begin{tabular}{cc}
\hline Extracts from fermentation/polysaccharide & Polysaccharide content $(\mathrm{mg} / \mathrm{ml})$ \\
\hline Brasenia schreberi polysaccharide (BSP) & $0.30 \pm 0.010$ \\
Micromonospora sp.YG-1 & $0.07 \pm 0.001$ \\
Xylariaceae sp. strain UT-X & $0.07 \pm 0.002$ \\
Psychrobacter pulmonis strain T-15 & $0.06 \pm 0.001$ \\
\hline
\end{tabular}

\subsection{Organic extracts of Endophytic Bacteria from B. schreberi Have Similar Peaks as Those of Polysaccharides from $B$. schreberi by HPLC}

We used HPLC to compare polysaccharide components detected in the bacterial species identified. HPLC spectra showed that the polysaccharide extracts from Micromonospora sp.YG-1 had a peak at $19 \mathrm{~min}$ and a sub-peak at $21 \mathrm{~min}$ (Figure 3(A)). Polysaccharide extracts from the other two endophytic bacteria, Xylariaceae sp. strain UT-X and Psychrobacter pulmonis strain T-15, also showed similar peaks (Figure 3(B), Figure 3(C)). Interestingly, the sub-peak at the $21^{\text {st }}$ min was similar to the peak signal of the polysaccharides extracted from B. schreberi (Figure 3(D)), which suggests that symbiotic bacteria in B. schrebe$r i$ can produce polysaccharides similar to $B$. schreberi polysaccharides, besides producing their species-specific polysaccharides.

\subsection{Polysaccharides Secreted by Three Endophytic Bacteria in B. schreberi Have Infrared Absorption Peaks Similar to Those of B. schreberi}

To further determine whether polysaccharides from endophytic bacteria and those from $B$. schreberi contain the same chemical functional groups, we performed FTIR (Fourier Transform infrared spectrum) analysis. Infrared spectrum analysis showed that the three symbiotic bacteria had similar infrared absorption peaks. Representative polysaccharides from Psychrobacter pulmonis strain T-15 showed nine characteristic absorption peaks (Figure 4). From the infrared spectra, it can be seen that the peak at $3392.79 \mathrm{~cm}^{-1}$ is the stretching vibration absorption peak of $-\mathrm{OH}$, while that at $2924.09 \mathrm{~cm}^{-1}$ is the stretching vibration absorption peak of $\mathrm{C}-\mathrm{H}$; these two are peaks that are characteristic of polysaccharides and similar to those of B. schreberi polysaccharides (Table 3). Peaks at $2854.65 \mathrm{~cm}^{-1}, 1558.00 \mathrm{~cm}^{-1}$ and $1458.18 \mathrm{~cm}^{-1}$ are the stretching vibration 


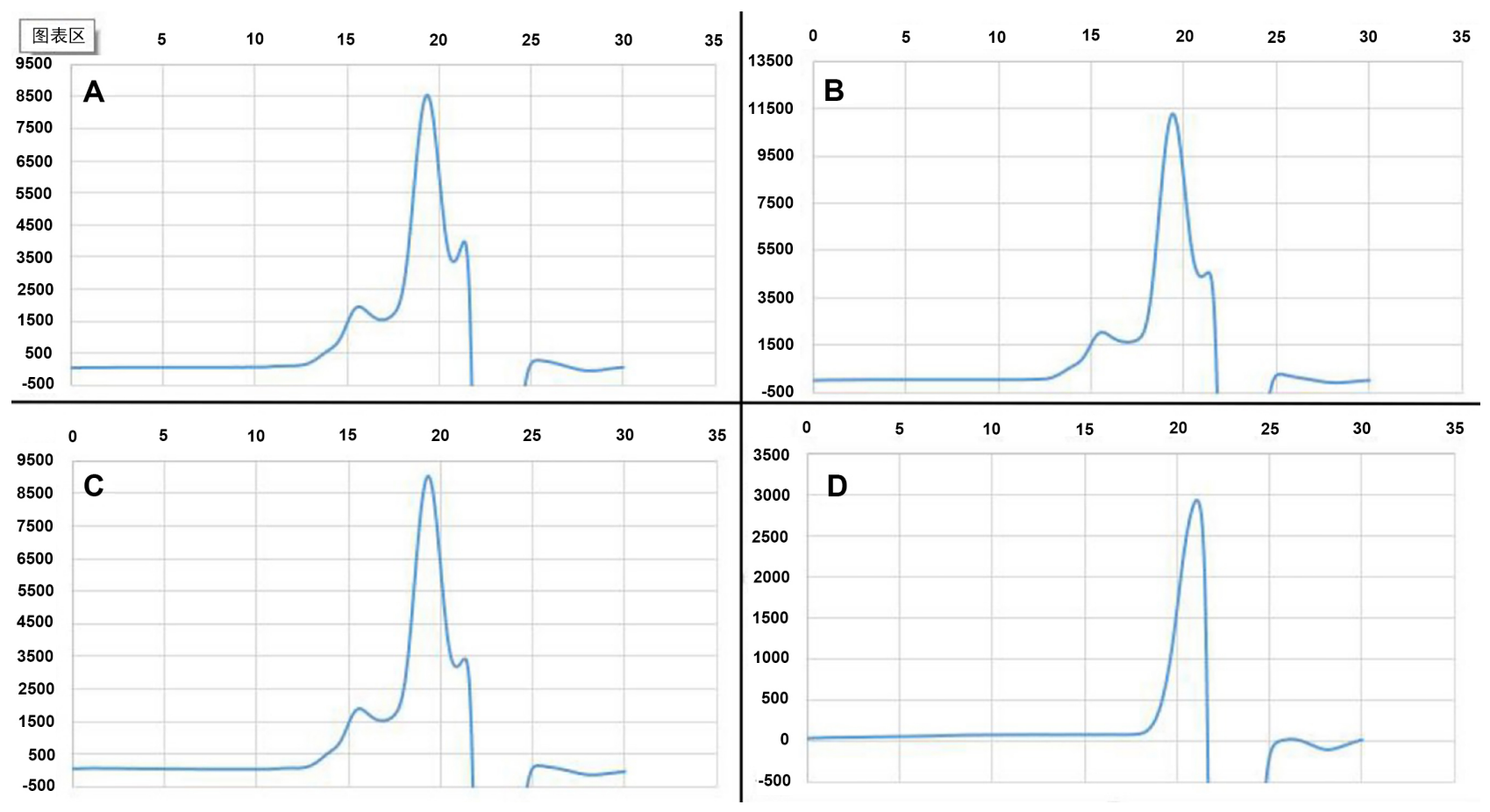

Figure 3. HPLC analysis of polysaccharides and secreted metabolites from Brasenia schreberi and its endophytic bacteria. (A) Micromonospora sp. YG-1; (B) Xylariaceae sp. strain UT-X; (C) Psychrobacter pulmonis strain T-15; (D) Brasenia Schreberi.

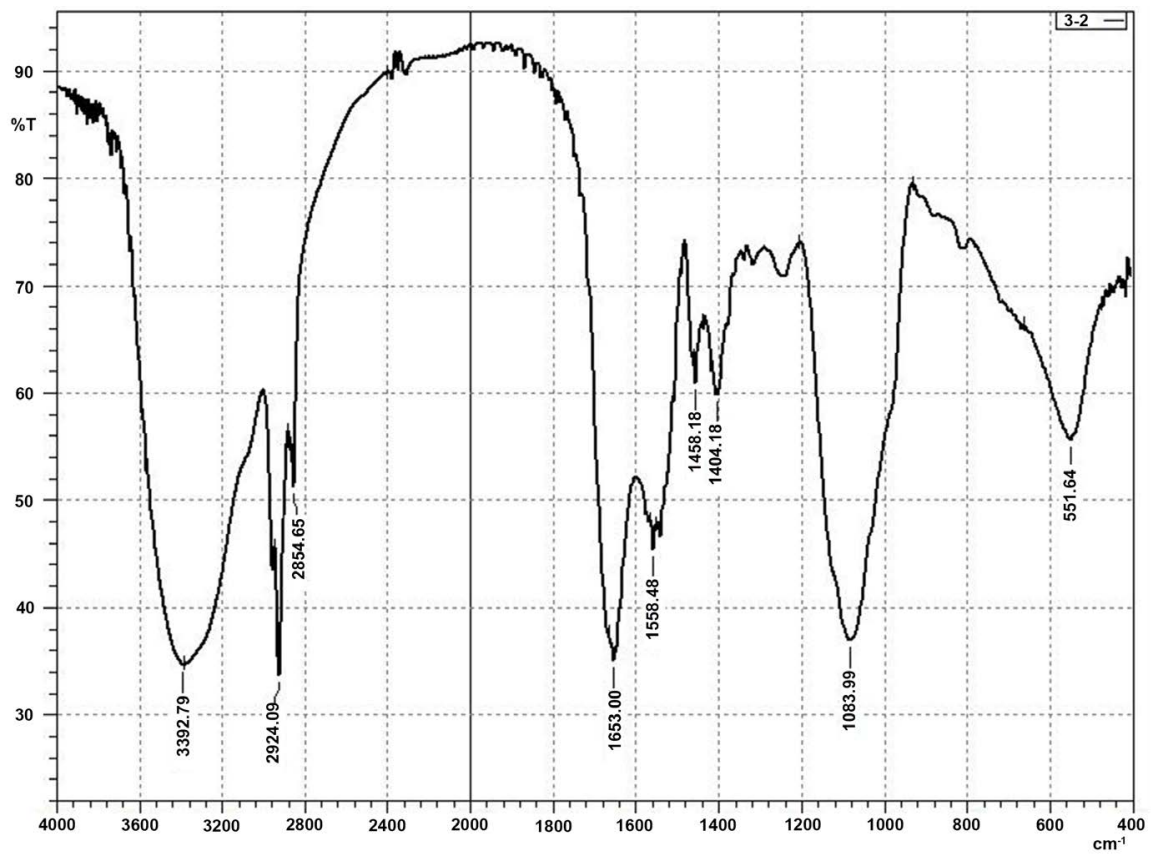

Figure 4. Infrared spectrum (IR) analysis of polysaccharides from Psychrobacter pulmonis strain T-15.

absorption peaks of $\mathrm{C}-\mathrm{H}$ on the benzene ring, which are characteristic spectrum peaks of polysaccharides that are specific of symbiotic bacteria (Table 3); the peak at $1653.00 \mathrm{~cm}^{-1}$ is the carbon-oxygen double bond $(\mathrm{C}=\mathrm{O})$ absorption peak; the peaks at $1404.18 \mathrm{~cm}^{-1}$ and $551.64 \mathrm{~cm}^{-1}$ are all $\mathrm{C}-\mathrm{H}$ stretching vibration 
Table 3. Characteristic peak analysis of polysaccharides from different species.

\begin{tabular}{|c|c|c|c|c|c|}
\hline $\begin{array}{l}\text { Band } \\
\left(\mathrm{cm}^{-1}\right) \\
\text { From }\end{array}$ & $\begin{array}{c}\text { Micromonospora } \\
s p .\end{array}$ & $\begin{array}{c}\text { Xylariaceae } \\
\text { sp. strain } \\
\text { UT-X }\end{array}$ & $\begin{array}{c}\text { Psychrobacter } \\
\text { pulmonis strain } \\
\text { T-15 }\end{array}$ & $\begin{array}{l}\text { Brasenia } \\
\text { schreberi }\end{array}$ & $\begin{array}{l}\text { Characterization of } \\
\text { chemical bonds }\end{array}$ \\
\hline 1 & 3385.07 & 3360.00 & 3392.79 & 3393 & $\mathrm{O}-\mathrm{H}$ \\
\hline 2 & 2926.01 & 2924.09 & 2924.09 & 2936 & $\mathrm{C}-\mathrm{H}$ \\
\hline 3 & 2854.65 & 2854.65 & 2854.65 & - & $\begin{array}{c}\mathrm{CH} 2 \text { from benzene } \\
\text { ring }\end{array}$ \\
\hline 4 & 1653.00 & 1651.07 & 1653.00 & $1719-1617$ & $\mathrm{C}=\mathrm{O}$ \\
\hline 5 & 1558.48 & 1556.55 & 1558.48 & - & $\begin{array}{c}\mathrm{CH} 2 \text { from benzene } \\
\text { ring }\end{array}$ \\
\hline 6 & 1458.18 & 1456.26 & 1458.18 & - & $\begin{array}{c}\mathrm{CH} 2 \text { from benzene } \\
\text { ring }\end{array}$ \\
\hline 7 & 1406.11 & 1404.18 & 1404.18 & - & $\mathrm{C}-\mathrm{H}$ \\
\hline 8 & 1083.99 & 1083.99 & 1083.99 & 1069 & $\mathrm{C}-\mathrm{O}$ \\
\hline 9 & - & - & - & $1420-1249$ & $\mathrm{C}-\mathrm{H}$ \\
\hline 10 & 549.71 & 551.64 & 551.64 & $550-429$ & $\mathrm{C}-\mathrm{H}$ \\
\hline
\end{tabular}

absorption peaks. Notably, the absorption peak at $1083.99 \mathrm{~cm}^{-1}$ is associated with the C-O-H bond, which is the characteristic peak of beta-glucan (Table 3).

In addition, the polysaccharide produced by the symbiotic bacteria had the same absorption peaks as those of $B$. schreberi at $3392.79 \mathrm{~cm}^{-1}$ and $2924.09 \mathrm{~cm}^{-1}$ (Table 3), as well as unique characteristic peaks $\left(2854.65 \mathrm{~cm}^{-1}, 1558.00 \mathrm{~cm}^{-1}\right.$ and $\left.1458.18 \mathrm{~cm}^{-1}\right)$. Further, polysaccharides from symbiotic bacteria and from $B$. schreberi showed the same characteristic peaks of beta-glucan at $1083.99 \mathrm{~cm}^{-1}$ (Table 3).

\subsection{Polysaccharides from Different Species Show Significant Inhibitory Effects on the Production of Hydroxyl Radicals}

The importance of polysaccharides lies in their physiological activities. The hydroxyl radical $(\mathrm{OH})$ is a type of free radical with strong oxidation ability. Its chemical nature is very active and its oxidation rate of various organic and inorganic substances is very high. It is the main factor causing lipid peroxidation, nucleic acid and protein breakdown and polysaccharide decomposition in tissues. It is related to aging, cancer, radiation damage and cell phagocytosis. To determine the biological activity of polysaccharides from symbiotic bacteria present in B. schreberi, the antioxidant activity of their polysaccharides was evaluated by analyzing the hydroxyl radical production system. The results showed that the inhibitory effect of polysaccharides from symbiotic bacteria on hydroxyl radical production was concentration-dependent and maximum at $1.0 \mathrm{mg} / \mathrm{ml}$ (Table 4). The free radical scavenging effect of polysaccharides from symbiotic bacteria on hydroxyl radicals was significantly higher than that of polysaccharides from B. Schreberi. 
Table 4. Inhibitory effect of polysaccharides from different species on hydroxyl radical production.

\begin{tabular}{cccc}
\hline \multirow{2}{*}{ Source of polysaccharide } & \multicolumn{3}{c}{ Inhibition efficiency (\%) } \\
\cline { 2 - 4 } & $0.5(\mathrm{mg} / \mathrm{ml})$ & $1.0(\mathrm{mg} / \mathrm{ml})$ & $2.0(\mathrm{mg} / \mathrm{ml})$ \\
\hline Polysaccharide from Brasenia schreberi & 19.46 & 27.82 & 45.39 \\
Micromonospora sp. YG-1 & 92.7 & 93.87 & 89.27 \\
Xylariaceae sp. strain UT-X & 93.29 & 92.47 & 92.01 \\
Psychrobacter pulmonis strain T-15 & 92.47 & 92.94 & 92.48 \\
\hline
\end{tabular}

\section{Discussion}

B. schreberi is an economically important aquatic plant that requires high-quality water [12] [13]. It is becoming increasingly pertinent to pursue an alternative way for the production of polysaccharides from water shield due to the continuous deterioration of its natural environment [12]. A distinctive anatomical feature of water shield is the distribution of stomata mainly on the adaxial leaf surface and the abundance of glandular cells on the abaxial leaf surface (Figure 1). In the transverse section of the stem, there is a thick layer of pectin on the surface and many glandular cells [17] It is preliminarily inferred that pectin is the product of glandular cell secretion and that the species' characteristic polysaccharide may be secreted by glandular cells or by endosymbiotic bacteria. In the present study, three species of bacteria were successfully isolated from sterilized stem and leaf tissues of B. schreberi and the polysaccharides they produce were studied. Three kinds of symbiotic bacteria were isolated and identified, in addition to one fungus (Figure 2, Table 1), reflecting the diversity of symbionts hosted by $B$. schreberi.

To determine whether the fermentation culture of symbiotic bacteria from $B$. schreberi contained polysaccharides, the polysaccharide content of the extract medium was determined by the DNS (3-amino-5-nitro salicylic acid) method and analyzed by HPLC (Table 2, Figure 3 ). The results confirmed that symbiotic bacteria in B. schreberi produce polysaccharides that show the same peaks on HPLC spectrum (Figure 3). IR showed that the polysaccharides from symbiotic bacteria and those from B. schreberi had similar IR characteristic peaks (Figure 4, Table 3). This is similar to the IR spectra of polysaccharides from the seaweeds, Asparagus [18] and Ganoderma lucidum [19]. This finding indicates that plant polysaccharides have similar or identical chemical functional groups. The function of a polysaccharide is reflected by its activity. The detection of hydroxyl free radicals indicated that polysaccharides from symbiotic bacteria present in $B$. schreberi remarkably inhibited the production of hydroxyl free radicals in a concentration-dependent manner (Table 4). Other biological activities of polysaccharides need to be further investigated using various cell types.

\section{Conclusions}

To circumvent the increasing deterioration of original living environment faced by $B$. schreberi in polysaccharide producing, seeking an alternative method to 
produce $B$. schreberi mucilage polysaccharide is of top priority. In this investigation, three endophytic bacteria were isolated and purified from B. schreberi, namely Micromonospora sp. YG-1, Xylariaceae sp. strain UT-X and Psychrobacter pulmonis strain $\mathrm{T}-15$. These endosymbiotic bacteria have the ability to produce polysaccharides with the similar retention time in HPLP analysis and FTIR spectrum that effectively scavenge reactive oxygen species. Our study provides a potential basis and feasible scheme for the comprehensive utilization of symbiotic bacteria in B. schreberi to produce effective natural polysaccharides.

\section{Acknowledgements}

This work was supported by the Special Fund for Basic Scientific Research of Central Colleges, South-Central University for Nationalities (CZP17051), National Natural Science Foundation of China (31270361) and Fund for Key Laboratory Construction of Hubei Province (Grant No.2018BFC360).

\section{Conflicts of Interest}

The authors declare that the research was conducted in the absence of any commercial or financial relationships that could be construed as a potential conflict of interest.

\section{References}

[1] Singdevsachan, S.K., Auroshree, P., Mishra, J., Baliyarsingh, B., Tayung, K. and Thatoi, H. (2016) Mushroom Polysaccharides as Potential Prebiotics with Their Antitumor and Immunomodulating Properties: A Review. Bioactive Carbohydrates and Dietary Fibre, 7, 1-14. https://doi.org/10.1016/j.bcdf.2015.11.001 https://www.sciencedirect.com/science/article/pii/S2212619815300164

[2] Xu, J. (2011) Structural Characterizations of Marine Microbial Exopolysaccharides and Their Antioxidatnt Activities. Dissertation, Ocean University of China, Qindao. (In Chinese) http://www.doc88.com/p-3713759441735.html

[3] Liu, Z. (2016) Examination of the Cytological Activity of a Novel Oligosaccharide. Dissertation, Tianjing Medical University, Tianjing. (In Chinese) http://www.doc88.com/p-2864919703394.html

[4] Xie, J.H., Tang, W., Jin, M.L., Li, J.E. and Xie, M.Y. (2016) Recent Advances in Bioactive Polysaccharides from Lycium barbarum L., Zizyphus jujuba Mill, Plantago spp. and Morus spp.: Structures and Functionalities. Food Hydrocolloids, 60, 148-160. https://www.sciencedirect.com/science/article/pii/S0268005X16301114 https://doi.org/10.1016/j.foodhyd.2016.03.030

[5] Fang, J.C., Wang, X.X., Lu, M.X., He, X.R. and Yang, X.H. (2018) Recent Advances in Polysaccharides from Ophiopogon japonicus and Liriope spicata var. prolifera. International Journal of Biological Macromolecules, 114, 1257-1266.

https://www.sciencedirect.com/science/article/pii/S0141813018301508 https://doi.org/10.1016/j.ijbiomac.2018.04.022

[6] Xiao, H., Cai, X., Fan, Y. and Luo, A. (2016) Antioxidant Activity of Water-Soluble Polysaccharides from Brasenia schreberi. Pharmacognosy Magazine, 12, 193-197. https://www.ncbi.nlm.nih.gov/pubmed/27601849 https://doi.org/10.4103/0973-1296.186343 
[7] Feng, S., Luan, D., Ning, K., Shao, P. and Sun, P. (2019) Ultrafiltration Isolation, Hypoglycemic Activity Analysis and Structural Characterization of Polysaccharides from Brasenia schreberi. International Journal of Biological Macromolecules, 135, 141-151. https://doi.org/10.1016/j.ijbiomac.2019.05.129 https://www.sciencedirect.com/science/article/pii/S0141813019322147?via\%3Dihub

[8] Ni, X.M., Yu, B., Zhou, Y.J. and Zhao, J.R. (1994) Studies on the Phylogenetic Relationships among the Nymphaeaceae. Journal of Wuhan Botanical Research, 12, 311-320. (In Chinese) http://www.whzwxyj.cn/EN/abstract/abstract713.shtml

[9] China Advanced Plant Atlas Compilation Group (1980) China Advanced Plant Atlas. Science Press, Beijing, 647-648. (In Chinese)

[10] Zhou, Y.F., Tang, Q.Y., Luo, X.W. and Wu, Y.Y. (2008) Study on Antioxidation Function in Vitro of Endopolysaccharide from Young Leaves of Brasenia schreberi. Food Science, No. 8, 78-79. (In Chinese) http://www.spkx.net.cn/EN/abstract/abstract13932.shtml\#

[11] Thompson, K.A., Sora, D.M., Cross, K.S., St. Germain, J.M. and Cottenie, K. (2014) Mucilage Reduces Leaf Herbivory in Schreber's Watershield, Brasenia schreberi J.F. Gmel. (Cabombaceae). Botany, 92, 412-416.

https://www.nrcresearchpress.com/doi/abs/10.1139/cjb-2013-0296\#.XTkr9XszaUl https://doi.org/10.1139/cjb-2013-0296

[12] Chen, W., Song, X.Y., Gong, H.Y., Geng, H., Qin, R., Xia, J., et al. (2017) Water Quality Analysis of Brasenia schreberi Living Environment in Lichuan. Botanical Research, 6, 71-78. https://doi.org/10.12677/BR.2017.62011 https://www.hanspub.org/journal/PaperInformation.aspx?paperID=20044

[13] Xie, C., Li, J., Pan, F., Fu, J., Zhou, W, Lu, S., et al. (2018) Environmental Factors Influencing Mucilage Accumulation of the Endangered Brasenia schreberi in China. Scientific Reports, 8, Article No. 17955.

https://www.nature.com/articles/s41598-018-36448-3 https://doi.org/10.1038/s41598-018-36448-3

[14] Guo, S.X. (2018) The Recent Progress and Prospects of Research on Endophytic Fungi in Medicinal Plants. Mycosystema, 37, 1-13. (In Chinese) http://www.cnki.com.cn/Article/CJFDTotal-JWXT201801001.htm

[15] Zhang, Z.D., Xie, Y.Q., Chu, M., Gu, M.Y., Song, S.Q., Tang, Q.Y., et al. (2010) Study on Isolation and Identification of Endophytes in Yam Rhizome. Xinjiang Agricultural Sciences, 47, 126-129. (In Chinese) http://en.cnki.com.cn/Article_en/CJFDTOTAL-XJNX201001024.htm

[16] Xu, G.H., Sun, W.Y., Jiang, F. and Ma, X.H. (1992) Studies on Ecological Distribution of Microorganism on the Surface of Junsai Leaves and on Factors Affecting Polysaccharides Fermentation by Mucilage-Producing Bacteria Strain 5242. Wuyi Science Journal, 9, 333-344. (In Chinese) http://en.cnki.com.cn/Article_en/CJFDTOTAL-WYKX199200041.htm

[17] Lv, J.L., Zhu, J.M. and Li, M. (1995) A Primary Study on Glandular Cell and Mucilage Producing Mechanism of Waters Shield. Journal of Zhejiang Agricultural University, 21, 314-318. (In Chinese) http://en.cnki.com.cn/Article_en/CJFDTOTAL-ZJNY503.023.htm

[18] Wen, L.R., Zhang, Y.L., Sun-Waterhouse, D.X., You, L.J. and Fu, X. (2017) Advantages of the Polysaccharides from Gracilaria Lemaneiformis over Metformin in Antidiabetic Effects on Streptozotocin-Induced Diabetic Mice. RSC Advances, 7, 9141-9157. https://doi.org/10.1039/C6RA26970B https://pubs.rsc.org/-/content/articlelanding/2017/ra/c6ra26970b\#!divAbstract 
[19] Ma, Y., He, H., Wu, J., Wang, C., Chao, K. and Huang, Q. (2018) Assessment of Polysaccharides from Mycelia of Genus Ganoderma by Mid-Infrared and Near-Infrared Spectroscopy. Scientific Reports, 8, Article No. 10.

https://www.nature.com/articles/s41598-017-18422-7

https://doi.org/10.1038/s41598-017-18422-7 


\section{Abbreviations Used}

BSP: Brasenia schreberi polysaccharide

FTIR: Fourier Transform infrared spectrum analysis

HPLC: High performance liquid chromatography

\section{Abstract Graph}

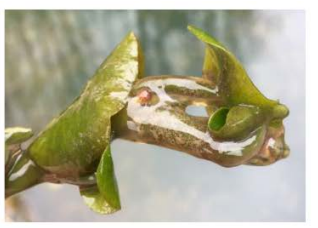

B. schreberi

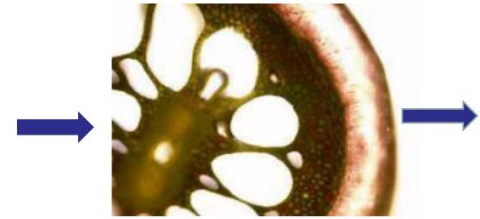

Anatomy of stem and leaf

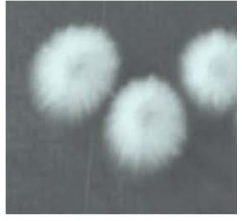

symbiotic enc

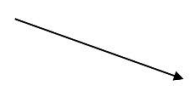

polysaccharide
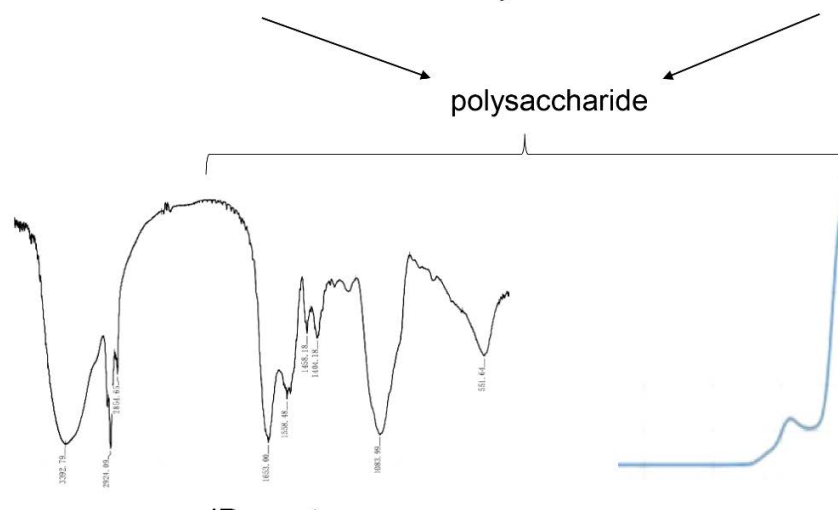

IR spectrum

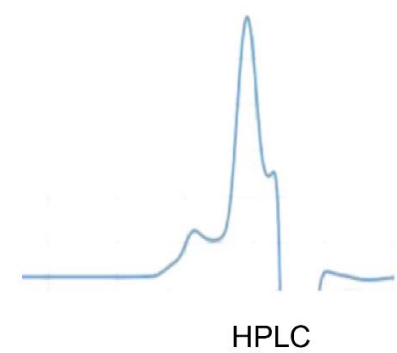

\section{Highlights}

The main component of viscous mucilage on the surface of $B$. schreberi is a viscous polysaccharide with exceptionally high nutritional value.

Three species of symbiotic endophytes of $B$. schreberi can produce the same or similar functional active ingredients of polysaccharide with the counterpart of B. schreberi.

The endosymbiotic bacteria have the promising application to produce polysaccharides and to circumvent the increasing deterioration of original living environment faced by $B$. schreberi in polysaccharide producing. 